\title{
Article \\ The Effects of Residential Built Environment on Supporting Physical Activity Diversity in High-Density Cities: A Case Study in Shenzhen, China
}

\author{
Yuan Gao ${ }^{1}$, Kun Liu ${ }^{1} * \mathbb{C}$, Peiling Zhou ${ }^{1}$ (I) and Hongkun Xie $^{2}$ \\ 1 Harbin Institute of Technology, School of Architecture, Shenzhen 518055, China; altiplano.39@163.com (Y.G.); \\ lindaplzhou@gmail.com (P.Z.) \\ 2 Gemdale Group South China Real Estate Company, Shenzhen 518016, China; xiehongkun@gemdale.com \\ * Correspondence: liuk@hit.edu.cn; Tel.: +86-134-8095-0600
}

Citation: Gao, Y.; Liu, K.; Zhou, P.; Xie, $\mathrm{H}$. The Effects of Residential Built Environment on Supporting Physical Activity Diversity in High-Density Cities: A Case Study in Shenzhen, China. Int. J. Environ. Res. Public Health 2021, 18, 6676. https:// doi.org/10.3390/ijerph18136676

Academic Editor: Paul B. Tchounwou

Received: 8 May 2021

Accepted: 19 June 2021

Published: 22 June 2021

Publisher's Note: MDPI stays neutral with regard to jurisdictional claims in published maps and institutional affiliations.

Copyright: (C) 2021 by the authors Licensee MDPI, Basel, Switzerland. This article is an open access article distributed under the terms and conditions of the Creative Commons Attribution (CC BY) license (https:// creativecommons.org/licenses/by/ $4.0 /)$.

\begin{abstract}
In high-density cities, physical activity (PA) diversity is an essential indicator of public health and urban vitality, and how to meet the demands of diverse PA in a limited residential built environment is critical for promoting public health. This study selected Shenzhen, China, as a representative case; combined the diversity of PA participants, types, and occurrence times to generate a comprehensive understanding of PA diversity; fully used data from multiple sources to measure and analyze PA diversity and residential built environment; analyzed the relationships between the built environment and PA diversity; and explored the different effects in clustered and sprawled high-density urban forms. PAs in clustered areas were two times more diverse than those in sprawled areas. Accessibility, inclusiveness, and landscape attractiveness of residential built environment jointly improved PA diversity. Clustered areas had significant advantages in supporting PA diversity since they could keep the balance between dense residence and landscape reservation with an accessible and inclusive public space system. The residential built environment with dense street networks, public traffic and service, multi-functional public space system, and attractive landscapes is crucial to improve the diverse PA to achieve more public health outputs in high-density cities. To promote health-oriented urban development, clustered urban form is advocated, and step-forward strategies should be carried out.
\end{abstract}

Keywords: physical activity diversity; residential built environment; healthy city; high-density city

\section{Introduction}

In the process of global urbanization, with increasing population densities, public health has gradually become the most urgent urban problem. The role of physical activity (PA) in promoting public health has been confirmed in many studies, such as by preventing chronic diseases and enhancing physical fitness [1], ensuring the physical health of adults and healthy development of children [2,3], guaranteeing residents' well-being and mental health, and promoting neighborhood communication [4-6]. The built environment was proven to influence PA significantly, in which residence and surroundings were believed to be the critical built environment to affect public health $[7,8]$. In western public healthoriented urban studies, a dense residence with mixed land use, high street connectivity, and large population were indicated to promote PA [9-13]. However, contrary to mainstream research results, high-density cities in Asia have not achieved improved public health outcomes. In the past 30 years, PA in Asia has been declining linearly [14], far below the world average level. Some studies have also found that low residential density is likely to promote PA [15]. This conclusion was also confirmed in many studies on metropolises of western countries [16,17]. Therefore, the consensus on general cities of Europe and America might not be suitable for high-density cities [18]. The discussions on the residential built environment of high-density cities should not only take into account the general 
built environment indicators but also be rooted in their local socio-economic and urban form characteristics.

In high-density cities, due to the high population density, the PAs are in great and diverse demands [19]. However, the land resources are scarce, and the built environment, especially the residential built environment, cannot provide sufficient space for activities [20]. Thus, improving PA diversity in a limited built environment is an important way for high-density cities to promote public health. Diversity refers to the abundance of things in a certain scope. Diversity is well known in ecology and sociology. It respects the heterogeneity of individuals as a whole and connotes equality and inclusive and continuous symbiosis among individuals. Diversity is the prerequisite and important sign of the vitality and sustainability of things [21,22]. Similarly, the diversity of PA, such as the gathering of a variety of PAs or different groups of people, is to characterize the vitality of a healthy behavior system in a built environment. It should reflect the heterogeneity of PA and the inclusive and symbiotic relationship among various activities [23], especially in high-density cities, since limited public space could not just serve one kind of PAs or a certain group. What the built environment supports is always a complex and mixed social phenomenon. In high-density cities, due to the dense population, it is important to regard PAs as a comprehensive system to meet the multivariate mixed PA demands. Only if we understand the complexity of PA diversity, we could find proper ways to improve the efficiency of a limited built environment on supporting flourishing public healthy life in high-density cities. However, in existing related research, although scholars had noticed the heterogeneity of PA, such as different PA participants [24] and different PA types [25], they were still focused on individual PA, and few studies aggregated PAs into a system to discuss PA diversity.

Back to the basic concept of PA, that is, the activity in which humans use muscles to produce energy consumption, in which there are three basic elements: people, activity forms, and processes to determine the differences of specific PAs in the real world [25,26]. Accordingly, PA diversity should cover at least three kinds of heterogeneity: the diversity of participants, the diversity of PA types, and the diversity of PA processes. The diversity of participants is that various people can perform PA fairly in the same public space, which reflects the fairness of the space to individuals. The diversity of PA types refers to that different activities perform synchronously, which signifies the inclusiveness of the spaces to activities. The diversity of PA processes can be understood as the different occurring times of activities, which indicates the overall continuity of PAs and also reflects the ability of the public space to support activities continuously. These three heterogeneities can collectively represent the fairness, inclusion, and continuous symbiosis among various PAs and fully describe the abundance of healthy behaviors in high-density cities (Figure 1). Based on the above understanding, this research aimed to represent the levels of PAs from a diversity perspective in high-density cities, to explore the relationship between the residential built environment and the PA diversity, and to put forward the planning and design strategies for the effective promotion on public health.

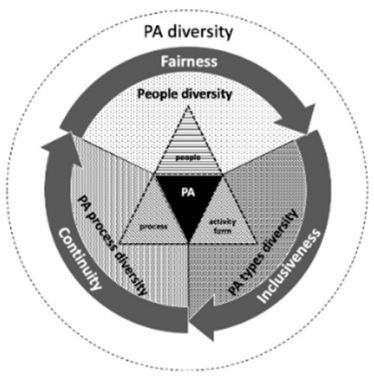

Figure 1. The conceptual model of PA diversity. 


\section{Methods}

\subsection{Research Area}

Shenzhen is located in the Pearl River Delta region of southern China, close to Hong Kong. It is the first city to open up as part of China's reform policy and is one of the core cities in the Guangdong-Hong Kong-Macao Greater Bay Area. Statistics from 2020 show that Shenzhen has an administrative area of $1997.47 \mathrm{~km}^{2}$, including $975.5 \mathrm{~km}^{2}$ for construction, with a service population of 20 million people. It is the city with the smallest area and largest population among all metropolises in China.

Shenzhen was established as a city in 1980, starting from the Shenzhen Special Economic Zone (SEZ), which was approximately $327.5 \mathrm{~km}^{2}$ and commonly referred to as "Inside Shenzhen". The SEZ carried out top-down urban construction as part of the overall urban planning, forming a sparse and orderly banded-cluster structure. Each cluster is with an appropriate scale (around $10 \mathrm{~km}^{2}$ ), has mixed land-use and high-density street networks, and is bordered by natural elements such as rivers and hills. Meanwhile, around the SEZ, the "Outside Shenzhen", covering more than $1600 \mathrm{~km}^{2}$, was built up in a disordered bottom-up way, with rapid urban sprawl along external traffic corridors. Due to the lack of forwarding planning management, the density of street networks and public services are much poorer than those inside the SEZ. As a result, two distinct urban forms were shaped: clustered and sprawled $[27,28]$. As shown in Figure 2, these two kinds of urban forms provided two typical high-density built environment samples for this research.

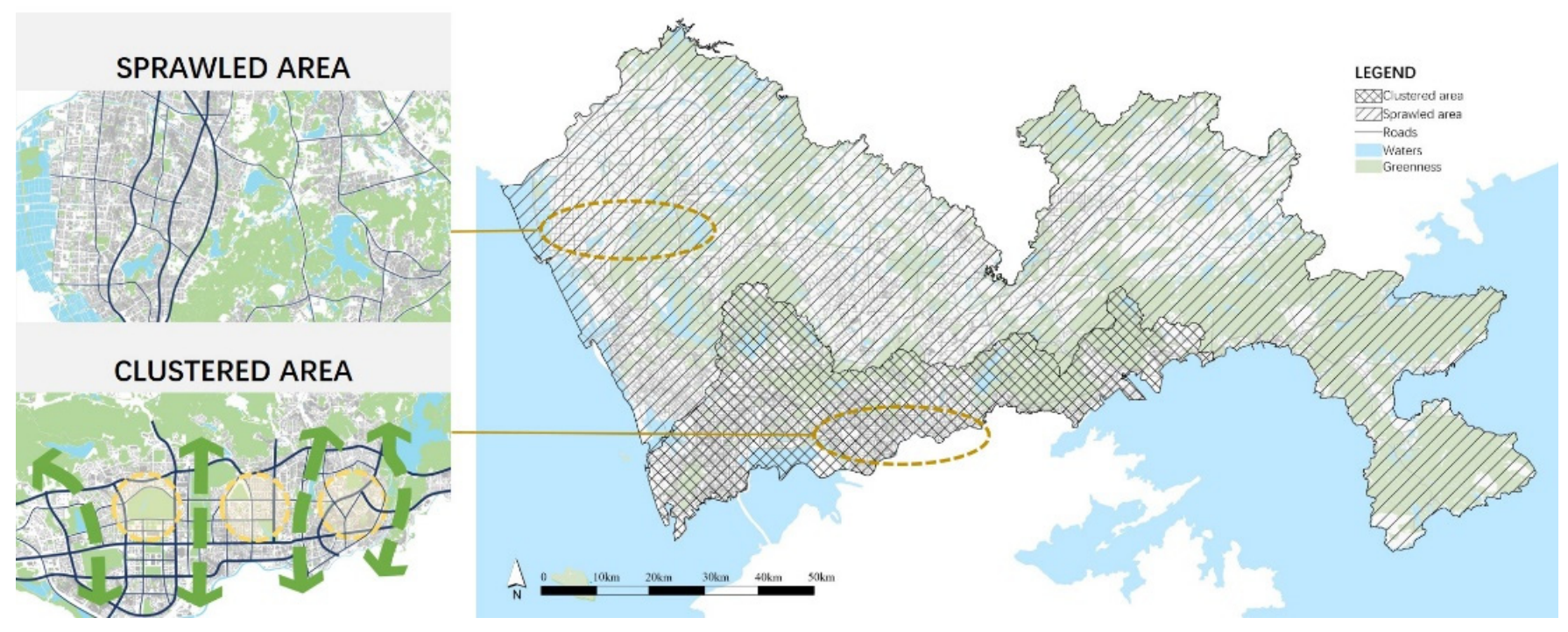

Figure 2. Schematic diagram of Shenzhen.

\subsection{Research Design}

Based on the comprehensive understanding of PA diversity, this research defined PA diversity as integrated characteristics of PA richness in terms of PA participants, PA types, and PA process. Considering the heterogeneity of Shenzhen's population was more based on social-economic attributes than on age or ethnicity since Shenzhen was a free-market-oriented young immigrant city, income was selected to present the PA participants' heterogeneity.

In this research, the residential built environment was defined as the neighborhoods where PAs occurred, including not only the residence where PAs started or ended but also the surrounding built environment where PA passed. Built environment indicators that affect PA diversity in existing research were summarized into four parts: accessibility, utility, inclusiveness, and landscape attractiveness. First of all, accessibility was commonly 
believed to support all kinds of PAs [29,30], in which access to service facilities and public transit positively supports walking and jogging [31-33], and the density of pedestrians and intersections can promote the presence of PAs $[11,12]$ and inspire PA in multiple social classes [34]. Secondly, the utilitarian aspects of the built environment, such as mixed land use and population density, have also been indicated to positively support PA types and different PA participants [35-42]. Further, studies have shown that the built environment also attracts more PAs by providing inclusive places and increasing sports facilities, such as playgrounds and greenways [43-46]. Meanwhile, the landscape attractiveness of the built environment, such as places with scenic spots and a high amount of green coverage, can continuously attract more kinds of PA effectively [44,47]. In summary, accessibility is a common feature of the built environment that supports almost all kinds of PAs, and the utility of the built environment provides the opportunity for PA occurrence. The inclusiveness of the place serves to promote the co-occurrence of multiple types of PA, and the landscape could attract various people and activities. We hypothesized that the residential built environment supported PA diversity by four characteristics: accessibility for people to perform PA, a utilitarian environment to provide an opportunity for different kinds of PAs, inclusiveness to support the co-occurrence of various PAs, and landscape attractiveness to gather various PAs. At the same time, we hypothesized that the effects of the residential built environment to support PA diversity were different between clustered and sprawled high-density urban forms.

\subsection{Data Resources}

\subsubsection{PA Data}

Compared with other types of PA, walking, jogging, and cycling are the most common PAs in cities [48]. These three activities do not rely on professional sports venues and equipment, mostly occur in urban public spaces, and are closely related to the built environment. This article selects walking, jogging, and cycling as the PA research objects and collects PA data through the PA tracking application Codoon, which is one of China's most popular self-tracking applications. With Codoon, people can track PA information (including the type of activity, time, speed, duration, and routes) and upload, share, and compare their workouts on social network platforms, which forms a natural VGI data pool. By the end of 2016, Codoon was the most commonly used PA tracking application in China, and the number of users in Shenzhen ranked among the top five Chinese cities [48]. Besides, the PA data from Codoon cover $24 \mathrm{~h}$, which can ensure comprehensive coverage of PA occurrence time. The majority of Codoon's users are young and middle-aged [49]. Similarly, the average age of the population in Shenzhen is relatively young, with a median age of 31.95 [50]. The structure of Codoon's users is similar to that of the population in Shenzhen, so the PA data from Codoon are representative in this research.

After counting the number of Codoon PA data in Shenzhen each month of 2015, it was found that the number of PAs was highest in spring and summer. On this basis, April and July were selected as typical time periods. The preliminary research also found that the number and the spatial distribution of daily PA data were relatively stable, with a difference between weekdays and weekends. Therefore, this study selected 8 days to collect daily full sample data, including two weekdays and two weekends in April and July.

To focus on the residential built environment, those samples that started or ended on residential land were chosen. All the PA data were divided into three types: the ones that started in residential land and ended in residential land, and those that started and ended in the same residential land. Those that started and ended in different residential areas were eliminated since it was hard to judge the living address of the participants. The housing price data from Home Link, which was the most popular housing transaction platform, were used to estimate the income of participants. There were 735 data, including 194 walking, 486 jogging, and 55 cycling data. 


\subsubsection{The Residential Built Environment Data}

The residential built environment data included: the Shenzhen Land-Use Survey (2014) from Shenzhen Land Use Master Plan (2006-2020), in which land was classified into nine types (residential land, commercial land, government and institutional land, industrial land, warehouse land, street land, infrastructure land, parklands, and other lands); street network data from the Open Street Map, including five types (motorway, primary, secondary, branch, and others); bus stop data from Baidu Map Point of Interest (2012); greenway networks from the Shenzhen Greenway Map (2013); sports facilities, restaurant data, service facilities (libraries, museums, cultural centers, hospitals, and banks), and scenic spots from the Scott Map (2016).

\subsection{Measurements}

\subsubsection{Measurements Unit}

In the field of geography, grid networks are often used as spatial units to analyze natural and social phenomena. The size of the grid used in general research is between $500 \mathrm{~m}$ and $1000 \mathrm{~m}[51,52]$. In the study of high-density cities or densely populated areas, a grid with a side length of $500 \mathrm{~m}$ is often used as a calculation unit [53-55]. To measure the characteristics of PA diversity and built environment, a $500 \mathrm{~m} \times 500 \mathrm{~m}$ grid [56-58] was used as the calculated unit $[59,60]$. By using the Fishnet Tool in ArcGIS, the land in Shenzhen was divided into grids; those without PAs were excluded, which left 2049 grids. Since the PA samples started or ended in residential land, the scope of the grids with PAs was defined as a residential built environment.

\subsubsection{Dependent Variable}

Based on the integrative definition, PA diversity is a comprehensive indicator that includes PA participant diversity (PAPD), PA type diversity (PATD), and PA occurrence time diversity (PAOD). Shannon's Diversity Index was used to measure diversity [61] (Table 1) since it was often used in the calculation of land use mixture $[13,62]$ and PA diversity [51]. The index varies between 0 and 1 ( 0 for maximum specialization, 1 for maximum diversification). PAPD referred to the abundance of the participants' income levels [63] (Equation (1)); PATD was the richness of different activities, including walking, jogging, and cycling (Equation (2)); PAOD was used to measure the diverse occurrence times from morning to night (Equation (3)).

Table 1. Measures of the three dimensions of PA diversity.

The Dimension of Diversity
Measure
PAPD $=\frac{\left\{-\sum_{k_{1}}\left[\left(p_{1}\right)\left(\ln p_{1}\right)\right]\right\}}{\ln k_{1}}$
where $k_{1}=$ number of social class types, according to income
$(k=4:$ lower-income class, low-income class, middle-income
class, high-income class); $p_{1}=$ the proportion of the PA
distance of each social class to the PA distance of all people in
each $500 \mathrm{~m}$ grid.
PATD $=\frac{\left\{-\sum_{k_{2}}\left[\left(p_{2}\right)\left(\ln p_{2}\right)\right]\right\}}{\ln k_{2}}$
where $k_{2}=$ number of physical activity types $(k=3:$ cycling,
walking, jogging); $p_{2}=$ the proportion of each type of activity
distance to all activity distances in each $500 \mathrm{~m}$ grid.
PAOD $=\frac{\left\{-\sum_{k_{3}}\left[\left(p_{3}\right)\left(\ln p_{3}\right)\right]\right\}}{\ln k_{3}}$
where $k_{3}=$ number of physical activity times $(k=4:$ from
$00: 00$ to $06: 00$, from $06: 00$ to $12: 00$, from $12: 00$ to $18: 00$, from
18:00 to $24: 00) ; p_{3}=$ the proportion of the PA distance of each
time period to the PA distance of all time periods in each
PAOD $500 \mathrm{~m}^{2}$ grid.


The income level of each participant was estimated by the housing price to income ratio (HPIR), which was 27.7 in 2015 [64]. The Joins tool in ArcGIS was used to assign housing price information to the residential lands of PA origin destinations to obtain the price per square meter of commercial housing where each participant lived, and then the annual family income was inferred by Equation (4). The income was divided into four categories: high-income level, middle-income level, low-income level, and lower-income level. (Table 2). Affordable housing and urban villages had no housing prices since they could not be traded. Considering relevant policies [65], people who lived in affordable housing were classified as low-income level. Additionally, because lower-income groups mostly live in urban villages [66], those participants from or to urban villages were defined as lower-income level.

Table 2. The classification standard of income level.

\begin{tabular}{cccc}
\hline Classification & HPIR & $\boldsymbol{y}$ & $\boldsymbol{n}$ \\
\hline high-income level & & $80 \mathrm{~m}^{2}[67]$ & $\geq 18,773$ USD [63,68] \\
middle-income level & $27.7[64]$ & $80 \mathrm{~m}^{2}[67]$ & $18,773-7509$ USD [63,68] \\
low-income level & & $60 \mathrm{~m}^{2}[67]$ & $7509-3755$ USD [63,68] \\
lower-income level & & $60 \mathrm{~m}^{2}[67]$ & $\leq 3755$ USD [63,68] \\
\hline
\end{tabular}

This is example 1 of an equation:

$$
n=\frac{m \times y}{H P I R}
$$

where HPIR was the housing price to income ratio; $m$ was the price per square meter of commercial housing; $y$ was the average residential area, and $n$ was the annual family income.

PA diversity was obtained by reducing the dimensions of PAPD, PATD, and PAOD using principal component analysis in SPSS [69]. The KMO was 0.812, which indicated the data were suitable for factor analysis, and Bartlett's Test of Sphericity was 0.000 to provide a reasonable basis for factor analysis. Table 3 showed that the result of principal component analysis had a high degree of interpretation.

Table 3. Total variance explained in the principal component analysis.

\begin{tabular}{lcccccc}
\hline & \multicolumn{3}{c}{ Initial Eigenvalues } & \multicolumn{2}{c}{ Extraction Sums of Squared Loadings } \\
\hline Component & Total & \%Variance & Cumulative\% & Total & \%Variance & Cumulative\% \\
Factor 1 & 2.339 & 77.981 & 77.981 & 2.339 & 77.981 & 77.981 \\
Factor 2 & 0.389 & 12.956 & 90.937 & - & - & - \\
Factor 3 & 0.272 & 9.063 & 100.00 & - & - & - \\
\hline
\end{tabular}

\subsubsection{Independent Variables}

According to the hypothesis, the residential built environment was measured from four aspects: accessibility, utility, inclusiveness, and landscape attractiveness. Accessibility included the street network density [11,12,34,43], bus stop station density [31], and public service facility density [32,33], which represented the accessibility of potential destinations in a city. Utility included the population density [40,70,71], restaurant density [72], and land use mixture [42-47,71], which directly reflected the utility of built environment. Inclusiveness included sports facility density [73] and the greenway network density [41]. Greenway is a linear public space that facilitates citizens moving close to natural resources such as rivers, lakes, and mountains [52], and it is generally designed for popular PAs such as walking, jogging, and cycling [53]. Sports facilities are also built to support diverse types of PAs. Landscape attractiveness included the green land ratio [47] and scenic spot density [74]. Indicators and measures are shown in Table 4. 
Table 4. Variables and measures of the residential built environment.

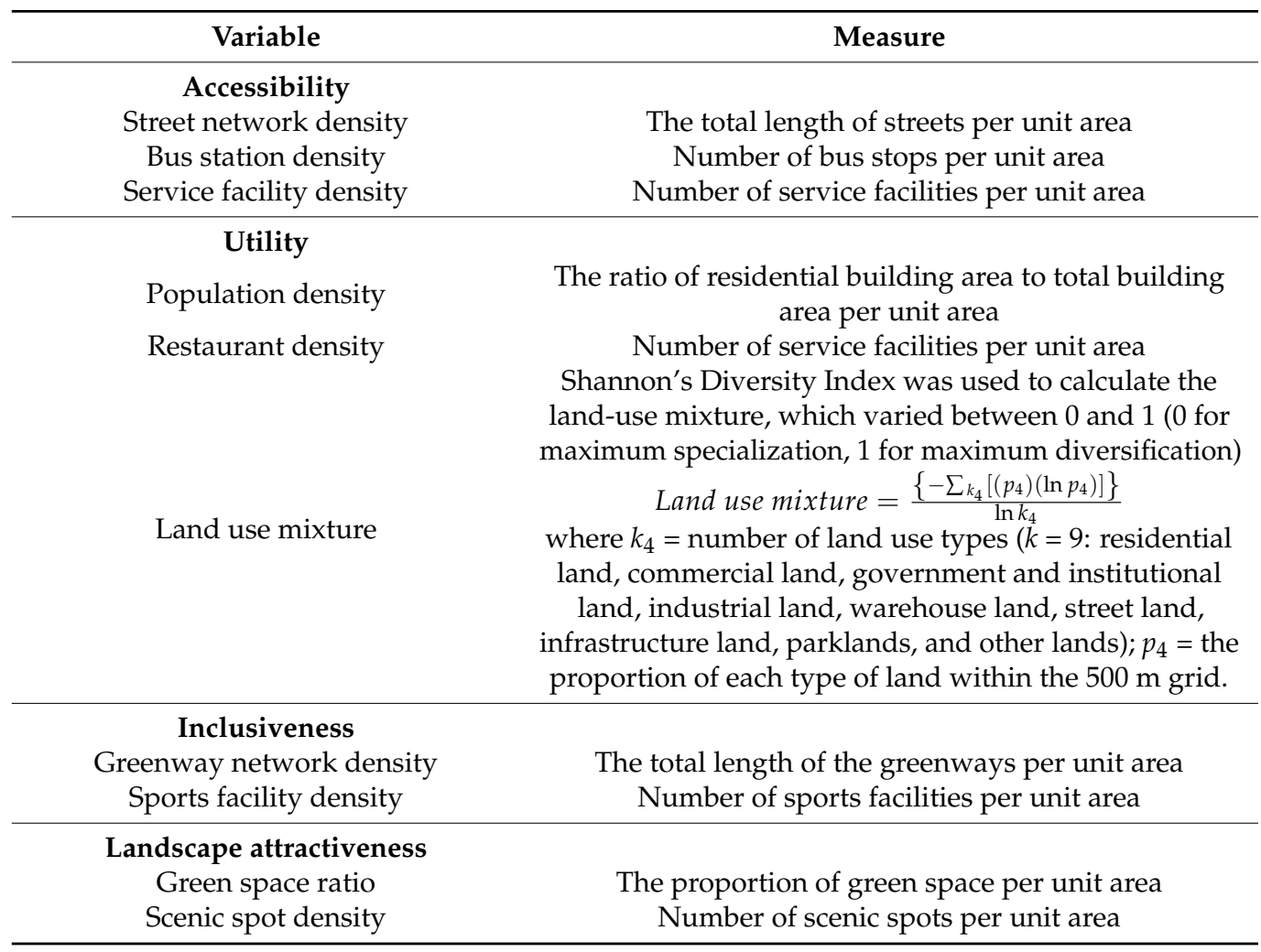

\subsubsection{Covariates}

Considering that PAs were affected by seasons and holidays, two control variables were selected: air temperature and weekend status. The highest daily average temperature in April was $28^{\circ} \mathrm{C}$, and the lowest daily average temperature in July was $28^{\circ} \mathrm{C}$ [75], this study selected $28{ }^{\circ} \mathrm{C}$ as a cut-off point: 1 for $28{ }^{\circ} \mathrm{C}$ and below, 0 for above $28^{\circ} \mathrm{C}$. Weekend status was measured by dichotomous variables, 1 for weekends and 0 for weekdays. Since PA data obtained from the internet did not contain individual attributes, personal factors were not discussed in the models.

\subsection{Data Merging and Statistical Analysis}

The PA and residential built environment data were overlaid in ArcGIS 10 with the Shenzhen local coordinate system to form the database. The Join tool in ArcGIS was used to link each feature value of the residential built environment with each $500 \mathrm{~m}$ grid corresponding to the PA diversity according to the label of each $500 \mathrm{~m}$ grid so that each grid had both PA diversity and built environment attribute. Each variable in each grid was averaged. SPSS was used for statistical and regression analyses to establish multivariate linear regression models to explore the association between PA diversity and the residential built environment. Three hypothetical models were made for the overall, clustered, and sprawled urban areas separately (Table 5). The collinearity diagnostics among the independent and control variables were performed before modeling, and the results showed no strong associations among the variables $(\mathrm{VIF}<10)$. To make valid inferences from the regression, this paper tested the residuals of the regression, and the residuals were normally distributed. 
Table 5. The hypothetical models.

\begin{tabular}{cccc}
\hline Variable & Model 1 & Model 2 & Model 3 \\
\cline { 2 - 4 } & Overall & Clustered Area & Sprawled Area \\
\hline Accessibility & & & \\
Street network density & Positive & Positive & Positive \\
Bus station density & Positive & Positive & Positive \\
Service facility density & Positive & Positive & Positive \\
\hline Utility & & & \\
Population density & Positive & Positive & Positive \\
The proportion of commercial land & Positive & Positive & Positive \\
Land use mixture & Positive & Positive & Positive \\
\hline Inclusiveness & & & \\
Greenway network density & Positive & Positive & Positive \\
Sports facility density & Positive & Positive & Positive \\
\hline Landscape attractiveness & & & \\
Green space ratio & Positive & Positive & Positive \\
Scenic spot density & Positive & Positive & Positive \\
Temperature $\leq 28{ }^{\circ} \mathrm{C}$ & Positive & Positive & Positive \\
Weekend & Positive & Positive & Positive \\
\hline
\end{tabular}

\section{Results}

\subsection{Descriptive Characteristics}

\subsubsection{PA Diversity and Spatial Distribution}

Among the 2049 spatial units, the mean value of PA diversity was 1.000. The comparison of PA diversity in clustered and sprawled areas indicated that the PAs in clustered areas were two times more diverse than those in sprawled areas (Table 6). Figure 3 shows that PA diversity was unevenly distributed in Shenzhen. The most diverse PAs were widely spread and exhibited line-like aggregation patterns in clustered areas along seasides, rivers, within large parks, and downtown residential areas. A few units with diverse PAs in the sprawled area presented a spot-like aggregation pattern in the downtowns.

Table 6. The description of PA diversity.

\begin{tabular}{ccccc}
\hline & Mean & Maximum & Minimum & Standard Deviation \\
\hline Clustered area & 1.5162 & 3.4100 & 0.0700 & 1.0351 \\
Sprawled area & 0.6767 & 3.2000 & 0.0000 & 0.8274 \\
Overall & 1.0000 & 3.4100 & 0.0000 & 1.0000 \\
\hline
\end{tabular}

\subsubsection{The Characteristics of the Residential Built Environment}

The statistical analysis showed the similarities and differences in the residential built environment in clustered and sprawled areas. As shown in Table 7, both areas had similar populations and land use mixtures. Because of the strict ecological control system and top-down overall greenway network constructions, the density of green resources and greenways were at the same level. However, scenic spots in the clustered area were dense and mostly accompanied by greenways (Figure 4). The street network, bus station, and public service in the clustered area were much denser to reflect a more accessible environment. Besides, the clustered area had much richer restaurants and sports facilities than in the sprawled area (Figure 5). In the clustered area, each cluster was organized in a network with complete facilities to form a self-sufficient unit, and clusters were divided by rivers, hills, and green belts to maintain many scenic spots. In the sprawled area, construction lands continuously expanded, and there was a lack of overall transportation and facility planning, which resulted in poor accessibility and insufficient facilities. 


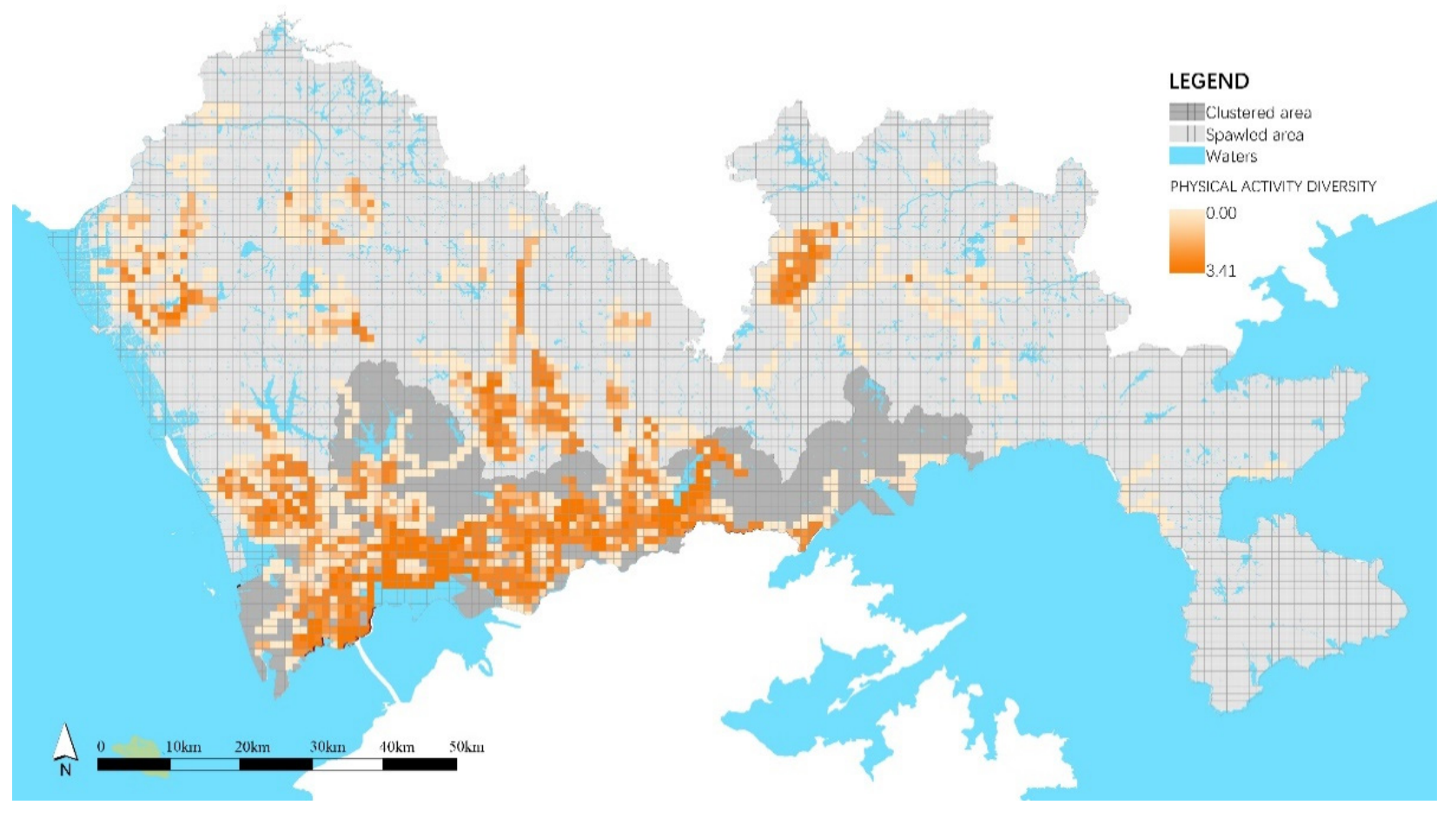

Figure 3. Spatial distribution of PA diversity.

Table 7. Description of the characteristics of the residential built environment.

\begin{tabular}{cccc}
\hline Variables & \multicolumn{3}{c}{ Mean } \\
\cline { 2 - 4 } & Overall & Clustered Area & Sprawled Area \\
\hline Accessibility & & & \\
Street network density $\left(\mathrm{km} / \mathrm{km}^{2}\right)$ & 8.484 & 12.220 & 6.141 \\
Bus station density $\left(\mathrm{Pcs} / \mathrm{km}^{2}\right)$ & 54.330 & 69.389 & 44.901 \\
Service facility density $\left(\mathrm{Pcs} / \mathrm{km}^{2}\right)$ & 32.015 & 39.849 & 27.110 \\
\hline Utility & & & \\
Population density (5900 person $\left./ \mathrm{km}^{2}\right)$ & 0.071 & 0.066 & 0.073 \\
Restaurants density (Pcs $\left./ \mathrm{km}^{2}\right)$ & 0.033 & 0.045 & 0.026 \\
Land use mixture & 0.454 & 0.468 & 0.446 \\
\hline Inclusiveness & & & \\
Greenway network density $\left(\mathrm{km} / \mathrm{km}^{2}\right)$ & 1.729 & 1.784 & 6.367 \\
Sports facility density $\left(\mathrm{Pcs} / \mathrm{km}^{2}\right)$ & 8.562 & 12.068 & \\
\hline Landscape attractiveness & & & 0.209 \\
Green space ratio & 0.208 & 0.206 & 1.053 \\
\hline Scenic spot density & 2.308 & 4.313 & \\
\hline
\end{tabular}




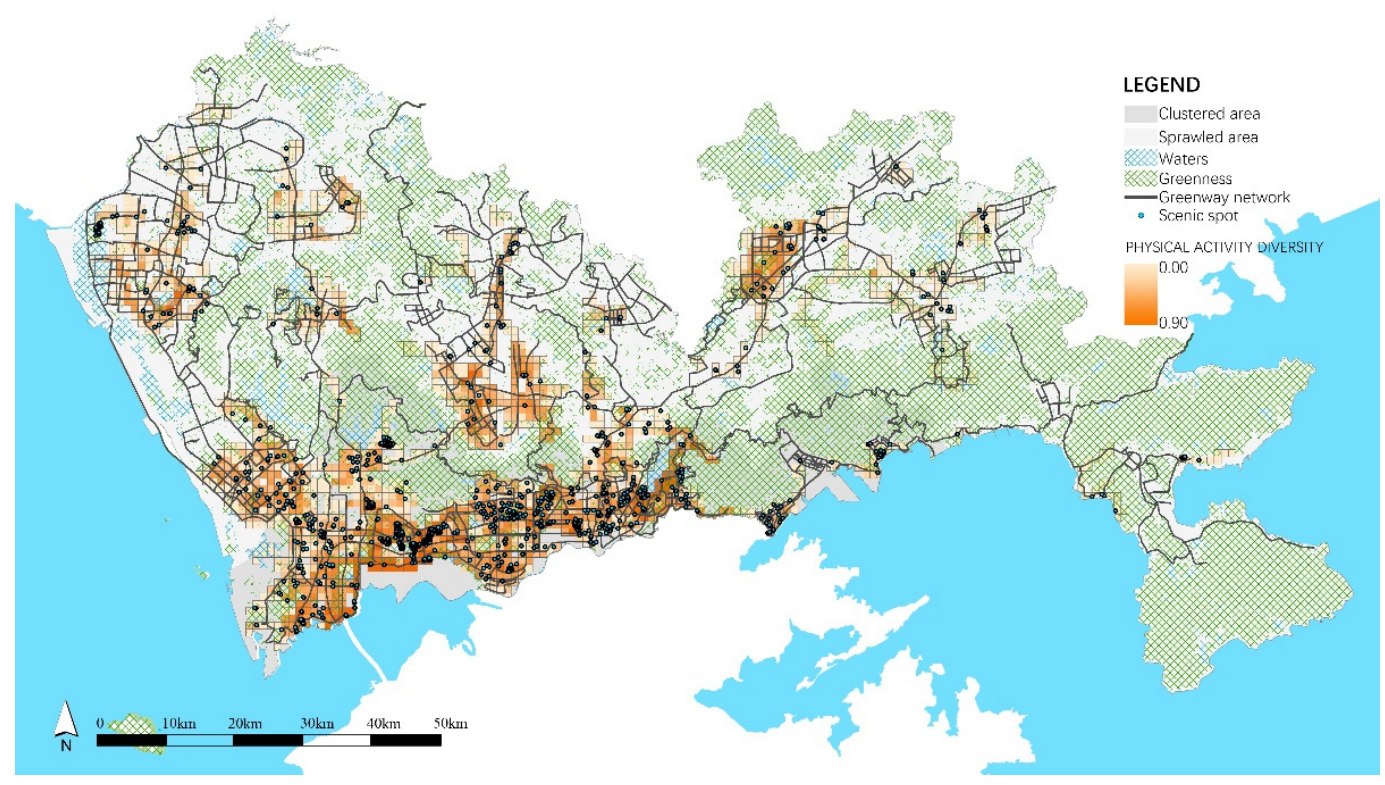

Figure 4. Spatial distribution of greenway network and scenic spots.

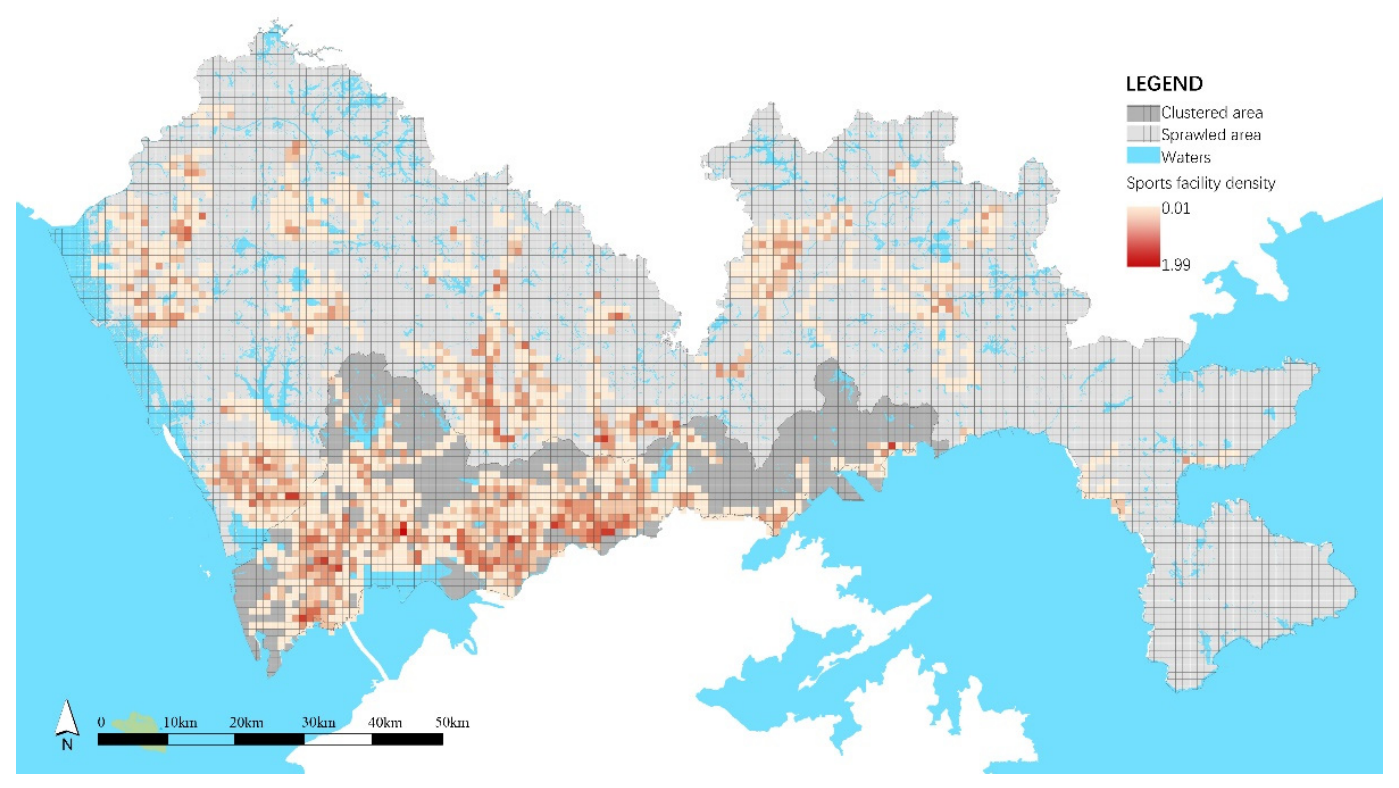

Figure 5. Spatial distribution of sports facility density.

\subsection{Statistical Modelling Results}

Three multivariate linear regression models were developed separately for the overall, clustered, and sprawled areas to explain and compare the relations between the residential built environment and PA diversity. The adjusted R squared presents the goodness of fit in the three models.

Table 8 shows the different results among the three models. In model 1, accessibility, inclusiveness, and landscape attractiveness were all positively related to PA diversity, and utility partly had negative effects. Comparing the results of models 2 and 3 , the accessibility and utility of the residential built environment were closely associated with PA diversity in the sprawled area and slightly affected PA diversity in the clustered area. While inclusiveness and landscape attractiveness were positively related to PA diversity in the clustered area, they contributed little to diversity in the sprawled area. In detail, 
PA diversity in the clustered area was positively associated with the green space ratio $(95 \%$ CI 0.010, 0.587; $p$ value $=0.043)$, greenway network density $(95 \%$ CI $0.104,0.181$; $p$ value $=0.000)$, sports facility density $(95 \%$ CI $0.002,0.010 ; p$ value $=0.008)$, and scenic spot density $(95 \%$ CI $0.001,0.009 ; p$ value $=0.010)$ and was negatively associated with the land use mixture $(95 \% \mathrm{CI}-0.997,-0.211 ; p$ value $=0.043)$. PA diversity in the sprawled area was positively associated with street network density $(95 \%$ CI $0.017,0.033 ; p$ value $=0.000)$, bus station density $(95 \%$ CI $0.000,0.002 ; p$ value $=0.050)$, service facility density $(95 \%$ CI $0.003,0.006 ; p$ value $=0.000)$, and greenway network density $(95 \%$ CI $0.002,0.057$; $p$ value $=0.032)$ and was negatively associated with population density $(95 \% \mathrm{CI}-1.553$, $-0.075 ; p$ value $=0.031)$.

Table 8. Regression models and results.

\begin{tabular}{|c|c|c|c|c|c|c|c|c|c|}
\hline \multirow{3}{*}{ Variables } & \multicolumn{9}{|c|}{ Mean } \\
\hline & \multicolumn{3}{|c|}{ Overall } & \multicolumn{3}{|c|}{ Clustered Area } & \multicolumn{3}{|c|}{ Sprawled Area } \\
\hline & B & Beta & Sig. & B & Beta & Sig. & B & Beta & Sig. \\
\hline \multicolumn{10}{|l|}{ Accessibility } \\
\hline Street network density & 0.025 & 0.183 & 0.000 & 0.005 & 0.038 & 0.242 & 0.025 & 0.178 & 0.000 \\
\hline Bus station density & 0.001 & 0.067 & 0.003 & 0.001 & 0.051 & 0.156 & 0.001 & 0.060 & 0.050 \\
\hline Service facility density & 0.003 & 0.117 & 0.000 & 0.001 & 0.038 & 0.409 & 0.004 & 0.206 & 0.000 \\
\hline \multicolumn{10}{|l|}{ Utility } \\
\hline Population density & -0.575 & -0.044 & 0.075 & -0.562 & -0.041 & 0.291 & -0.814 & -0.077 & 0.031 \\
\hline Restaurants density & -0.001 & -0.033 & 0.254 & 0.000 & 0.037 & 0.411 & -0.001 & -0.022 & 0.613 \\
\hline Land use mixture & -0.235 & -0.043 & 0.050 & -0.604 & -0.105 & 0.003 & -0.023 & 0.005 & 0.868 \\
\hline \multicolumn{10}{|l|}{ Inclusiveness } \\
\hline Greenway network density & 0.065 & 0.103 & 0.000 & 0.142 & 0.221 & 0.000 & 0.030 & 0.057 & 0.032 \\
\hline Sports facility density & 0.005 & 0.073 & 0.003 & 0.006 & 0.103 & 0.008 & -0.001 & -0.010 & 0.774 \\
\hline \multicolumn{9}{|l|}{ Landscape } & \\
\hline Green space ratio & 0.260 & 0.067 & 0.003 & 0.297 & 0.076 & 0.043 & 0.057 & 0.017 & 0.578 \\
\hline Scenic spot density & 0.008 & 0.084 & 0.000 & 0.005 & 0.076 & 0.010 & 0.006 & 0.024 & 0.331 \\
\hline Weekend & 0.525 & 0.263 & 0.000 & 0.794 & 0.356 & 0.000 & 0.314 & 0.190 & 0.000 \\
\hline Temperature $\leq 28{ }^{\circ} \mathrm{C}$ & 0.529 & 0.258 & 0.000 & 0.595 & 0.251 & 0.000 & 0.443 & 0.268 & 0.000 \\
\hline Constant & -1.015 & & 0.000 & -0.717 & - & 0.000 & -1.007 & - & 0.000 \\
\hline Adjusted R square & \multicolumn{3}{|c|}{0.371} & \multicolumn{3}{|c|}{0.366} & & \multicolumn{2}{|l|}{0.291} \\
\hline
\end{tabular}

\section{Discussion}

\subsection{The Important Role of Accessibility}

The results show that the accessibility of the residential built environment is positively associated with PA diversity in the overall and sprawled areas, which indicates the significance of street network density, bus stop density, and service facility density for supporting diverse and vital physical activities. However, this relationship was not significant in the clustered area.

As shown in Table 7, the accessibility of the residential built environment in the clustered area was much higher than that in the sprawled area. Taking 0.5 as the dividing point, the PA diversity was divided into high and low parts. The comparison of the accessibility between high and low parts indicated that there was no significant difference in the clustered area, while in the sprawled area, the accessibility of the high part was twice that of the low part. Within the high parts, the accessibility in the clustered area was the same as that in the sprawled area. Because of the generally high accessibility in the clustered area, there were no significant relations between accessibility and PA diversity, so the irrelevance result did not mean that accessibility was not important in the clustered area. On the contrary, an accessible built environment with a dense street network, public traffic, and public service played necessary roles to activate various physical activities. 


\subsection{The Negative Effects of Utility on PA Diversity}

The results showed that the utility of the residential built environment was negatively correlated with PA diversity, in which land use mixtures reduced PA diversity in the clustered area, and population density had negative effects on PA diversity in the sprawled area. Preliminary research has shown that a high land-use mixture and dense restaurants could enhance individual travel and induce individual PA [44]. However, the residential areas with the dense and mixed-use built environment are often located in downtowns, where it is difficult to provide enough space to gather for various types of PA. To date, dense and mixed-use residential blocks had failed to provide spaces for various PAs to achieve healthy vitality.

\subsection{The Co-Occurrence Effects of Inclusiveness on PAs}

In both clustered and sprawled areas, the greenway network density was found to play a significant role in promoting PA diversity. This also reflected that the greenways effectively support different kinds of activities since they were specially designed for various PAs. Since 2010, a total of $2448 \mathrm{~km}$ of greenways was built, forming a large and homogeneous greenway network throughout Shenzhen (Figure 3), which provided almost the same opportunities to attract various PAs in both clustered and sprawled areas and achieved co-occurrence effects to support diverse PAs. In addition, sports facility density was found to promote PA diversity in the clustered area, while it had no effect in the sprawled area. As a professional public service for PA, sports facilities are undoubtedly capable of attracting diverse PAs. In the clustered area, sports facilities and the greenway network together formed a system to support diverse PAs, while in the sprawled area, due to weak planning and the backward stage of development, the number of sports facilities was in short supply, and they were not integrated with the greenway network, which failed to promote PA diversity.

\subsection{The Aggregation Effects of Landscape Attractiveness on PA Diversity}

In models 1 and 2, the green space ratio and scenic spot density were positively correlated with PA diversity. Overlapping the green lands, scenic spots, and PA diversity (Figure 4), it was clear that places with rich green and scenic spots corresponded to high PA diversity, which showed clear aggregation effects on diverse PAs. Unlike greenways and sports facilities, which functionally support various types of PA, places with good landscapes provide rich visual and mental experiences, so they have become popular destinations that can aggregate diverse PAs. In the sprawled area, green lands were as rich as those in the clustered area, but because of the marginal spatial distribution and poor accessibility, they were difficult to reach and use. Meanwhile, the sparse scenic spots of the residential built environment resulted in weak attractiveness, thus failing to gather diverse PAs.

\subsection{The Joint Effects of the Built Environment on PA Diversity}

Based on the above discussions, we found because of the overall PA-friendly travel environment, the evenly distributed multi-functional public space systems, and rich landscape, the clustered area provided sufficient accessible, inclusive, and attractive places for various PAs to achieve high PA diversity. Meanwhile, in sprawled areas, although the greenway networks and green spaces were as rich as those in clustered areas, the poor accessibility, sparse, and discrete public space system still cause to attract diverse PAs. These results indicate the joint effects among accessibility, inclusiveness, and landscape attractiveness of built environment on PA diversity, in which accessibility is the fundamental and necessary condition to provide possibilities for people to go outside and perform various PAs, inclusive public systems such as greenways with dense sports facilities can functionally support the co-occurrence of various PAs to improve diversity, and good landscapes further trigger rich activity experiences to strengthen the aggregation of various PAs, thus resulting in increased PA diversity. 


\subsection{Advantages of Clustered Areas for Promoting Healthy and Vital Urban Life in High-Density Cities}

An accessible, inclusive, and attractive residential built environment is important to improve PA diversity and promote the vitality of a healthy city. However, in high-density cities, crowded and expanded urban construction easily results in poor accessibility, scarce public space, and less attractive landscapes. In this research, compared with sprawled areas, clustered areas successfully supported PA diversity, which indicated the advantages of clustered urban form. In SEZ, the city was divided into several clusters with appropriate size by natural reservations such as rivers and hills, and each cluster was built with a dense street network and services with systemic public space to form an integrally organic and inner compact living unit, then achieved accessible, inclusive, and attractive built environment on supporting various PAs. In high-density cities, it is crucial to maintain the balance between dense residence and landscape reservation and build up an accessible and inclusive public space system such as a greenway network for promoting healthy and vital urban life.

\subsection{Limitations}

This study fully utilized big data from multiple sources, including traditional statistics, PA VGI, and open-source data such as POIs and housing prices. Because it was difficult to guarantee the same acquisition times for multi-source data, the combined analysis of data might lead to errors and affect the accuracy of the results. Meanwhile, due to the limitation of data collection methods, providers of PA VGI data were probably young and modern people; accordingly, the descriptions and measures of PA might not be generalized. Furthermore, due to defects in PA VGI data, the individual characteristics of PA participants could not be included in the models, resulting in the insufficient explanatory ability of the study. An offline social survey of Codoon users should be added for collecting more demographic information to improve the accuracy of the model in future studies.

\section{Conclusions}

This study identifies the importance of PA diversity in public health research in highdensity cities. PA diversity was defined as a comprehensive concept that contains PA participant diversity, PA type diversity, and PA occurrence time diversity to indicate the fairness, inclusive, and continuous symbiosis among various PAs and the abundance of healthy behaviors. The systematic discussion of PA diversity provides a new way for research on PAs in the field of urban planning and design, especially in the context of high-density urbanization all over the world.

The correlation analysis revealed the joint relationships between the residential built environment and PA diversity in high-density cities. Accessibility is the fundamental condition to activate individual PAs, inclusiveness supports the co-occurrence of various PAs to consolidate PA diversity, and landscape attractiveness furtherly aggregates multiple PAs.

The research also found that the PA diversity in the clustered area was higher than that in the sprawled area. This result occurred because the clustered urban form structurally maintained the balance between dense residence and landscape reservation with an accessible and inclusive public space system. To promote health-oriented urban planning and development in high-density cities, the clustered urban structure should be advocated, and step-forward strategies should be carried out: first, to promote the overall accessibility of the residential built environment to promote PA; second, to build an inclusive public space system for the co-occurrence of various types of PAs; and further, to improve the attractiveness of landscapes to aggregate PAs for higher diversity. In summary, creating an accessible, inclusive, and attractive residential built environment is a crucial way to synchronously support various PAs to improve the vitality of public health in high-density cities. 
Author Contributions: Conceptualization, K.L., Y.G., and P.Z.; methodology, K.L. and Y.G.; software, K.L. and Y.G.; formal analysis, K.L. and Y.G.; data collection, H.X.; writing-original draft preparation, K.L. and Y.G.; writing-review and editing, K.L. and Y.G. All authors have read and agreed to the published version of the manuscript.

Funding: This research was funded by the National Natural Science Foundation of China, Grant number 51508126, the National Key Research and Development Program of China, Grant number 2019YFD1100802 and 2019YFD1100804

Institutional Review Board Statement: Not applicable.

Informed Consent Statement: Not applicable.

Data Availability Statement: Publicly available datasets were analyzed in this study. The PA data in this study were collected from Codoon, it is one of China's most popular self-tracking applications. Its data is publicly available. Users of Codoon can view the activity information of other users by logging in to the official website and registering an account for free.

Acknowledgments: We thank the National Natural Science Foundation of China (Grant No. 51508126) for the support of the study and the preparation of this paper. The research was also partially supported by the National Key Research and Development Program of China, Grant number 2019YFD1100802 and 2019YFD1100804 for physical activity VGI data collection and processing.

Conflicts of Interest: The authors declare no conflict of interest.

\section{References}

1. Dishman, R.K.; Heath, G.W.; Lee, I.-M. Physical Activity Epidemiology; Human Kinetics: Champaign, IL, USA, 2012.

2. Nelson, M.E.; Rejeski, W.J.; Blair, S.N.; Duncan, P.W.; Judge, J.O.; King, A.C.; Macera, C.A.; Castaneda-Sceppa, C. Physical activity and public health in older adults: Recommendation from the American College of Sports Medicine and the American Heart Association. Circulation 2007, 116, 1094-1105. [CrossRef]

3. Ng, Q.X.; Ho, C.Y.X.; Chan, H.W.; Yong, B.Z.J.; Yeo, W.-S. Managing childhood and adolescent attention-deficit/hyperactivity disorder (ADHD) with exercise: A systematic review. Complement. Ther. Med. 2017, 34, 123-128. [CrossRef] [PubMed]

4. Liu, H.; Li, F.; Li, J.; Zhang, Y. The relationships between urban parks, residents' physical activity, and mental health benefits: A case study from Beijing, China. J. Environ. Manag. 2017, 190, 223-230. [CrossRef]

5. Yin, C.; Zhang, J.; Shao, C. Relationships of the multi-scale built environment with active commuting, body mass index, and life satisfaction in China: A GSEM-based analysis. Travel Behav. Soc. 2020, 21, 69-78. [CrossRef]

6. Wang, X.; Shao, C.; Yin, C.; Guan, L. Disentangling the comparative roles of multilevel built environment on body mass index: Evidence from China. Cities 2021, 110, 103048. [CrossRef]

7. Lawrence, F.; Kavage, S.; Devlin, A. Health and the Built Environment: A Review; The Canadian Medical Association, Urban Design 4 Health, Ltd.: Vancouver, BC, Canada, 2012.

8. Alfonzo, M.; Boarnet, M.G.; Day, K.; Mcmillan, T.; Anderson, C.L. The relationship of neighbourhood built environment features and adult parents' walking. J. Urban Des. 2008, 13, 29-51. [CrossRef]

9. Frank, L.; Engelke, P.; Schmid, T. Health and Community Design: The Impact of the Built Environment on Physical Activity; Island Press: Washington, DC, USA, 2003.

10. Frank, L.D.; Schmid, T.L.; Sallis, J.F.; Chapman, J.; Saelens, B.E. Linking objectively measured physical activity with objectively measured urban form: Findings from SMARTRAQ. Am. J. Prev. Med. 2005, 28, 117-125. [CrossRef]

11. Cao, X.; Handy, S.L.; Mokhtarian, P.L. The influences of the built environment and residential self-selection on pedestrian behavior: Evidence from Austin, TX. Transportation 2006, 33, 1-20. [CrossRef]

12. Chatman, D.G. Residential choice, the built environment, and nonwork travel: Evidence using new data and methods. Environ. Plan. A 2009, 41, 1072-1089. [CrossRef]

13. Frank, L.D.; Pivo, G. Impacts of mixed use and density on utilization of three modes of travel: Single-occupant vehicle, transit, and walking. Transp. Res. Rec. 1994, 1466, 44-52.

14. Li, F. Physical activity and health in the presence of China's economic growth: Meeting the public health challenges of the aging population. J. Sport Health Sci. 2016, 5, 258-269. [CrossRef] [PubMed]

15. Forsyth, A.; Oakes, J.M.; Schmitz, K.H.; Hearst, M. Does residential density increase walking and other physical activity? Urban Stud. 2007, 44, 679-697. [CrossRef]

16. Chaudhury, H.; Mahmood, A.; Michael, Y.L.; Campo, M.; Hay, K. The influence of neighborhood residential density, physical and social environments on older adults' physical activity: An exploratory study in two metropolitan areas. J. Aging Stud. 2012, 26, 35-43. [CrossRef]

17. Saxton-Ross, A. Physical Activity and the Urban Form: How the Built Environment, Residential Density, Residential Segregation, Income Inequality, Race, Gender and Education, Influence Physical Activity in Atlanta. Ph.D. Thesis, Howard University, Ann Arbor, MI, USA, 2009; p. 188. 
18. Chen, T.-L.; Chiu, H.-W.; Lin, Y.-F. How do East and Southeast Asian Cities Differ from Western Cities? A Systematic Review of the Urban Form Characteristics. Sustainability 2020, 12, 2423. [CrossRef]

19. He, H.; Li, T.; Yu, Y.; Lin, X. Associations between Built Environment Characteristics and Walking in Older Adults in a HighDensity City: A Study from a Chinese Megacity. Front. Public Health 2020, 8, 577140. [CrossRef]

20. Howley, P.; Scott, M.; Redmond, D. Sustainability versus liveability: An investigation of neighbourhood satisfaction. J. Environ. Plan. Manag. 2009, 52, 847-864. [CrossRef]

21. Banister, D.; Hickman, R. How to design a more sustainable and fairer built environment: Transport and communications. In IEE Proceedings-Intelligent Transport Systems; IET: London, UK, 2006; pp. 276-291.

22. Talen, E. Design for Diversity; Routledge: London, UK, 2012.

23. Wang, M.; Qiu, M.; Chen, M.; Zhang, Y.; Zhang, S.; Wang, L. How does urban green space feature influence physical activity diversity in high-density built environment? An on-site observational study. Urban For. Urban Green. 2021, 62, 127129. [CrossRef]

24. Thompson, C.W. Urban open space in the 21st century. Landsc. Urban Plan. 2020, 60, 59-72. [CrossRef]

25. Lee, R.E.; Cubbin, C.; Winkleby, M. Contribution of neighbourhood socioeconomic status and physical activity resources to physical activity among women. J. Epidemiol. Community Health 2007, 61, 882-890. [CrossRef]

26. WHO. WHO Guidelines on Physical Activity and Sedentary Behaviour, Guideline. 2020. Available online: https://www.who. int/publications/i/item/9789240015128 (accessed on 25 November 2020).

27. Wang, F. Urban Planning in Shenzhen: Impact and Reply in Rapid Growth. Urban Plan. Forum 2008, 02, 17-23.

28. Liu, K.; Li, G.; Yin, X.; Xu, L. Towards Multi-dimensional Flexibility: The Evolution of Planning. Urban Plan. Forum 2012, 01, 63-70.

29. Tang, W.; Mokhtarian, P.L.; Handy, S.L. The impact of the residential built environment on work at home adoption and frequency: An example from Northern California. J. Transp. Land Use 2011, 4, 3-22.

30. Humpel, N.; Owen, N.; Leslie, E. Environmental factors associated with adults' participation in physical activity: A review. Am. J. Prev. Med. 2002, 22, 188-199. [CrossRef]

31. Lee, S.A.; Ju, Y.J.; Lee, J.E.; Hyun, I.S.; Nam, J.Y.; Han, K.-T.; Park, E.-C. The relationship between sports facility accessibility and physical activity among Korean adults. BMC Public Health 2016, 16, 893. [CrossRef] [PubMed]

32. Wang, Z.; Lee, C. Site and neighborhood environments for walking among older adults. Health Place 2010, 16, 1268-1279. [CrossRef] [PubMed]

33. An, R.; Zheng, J. Proximity to an exercise facility and physical activity in China. Southeast Asian J. Trop. Med. Public Health 2014, $45,1483$.

34. Su, M.; Tan, Y.-Y.; Liu, Q.-M.; Ren, Y.-J.; Kawachi, I.; Li, L.-M.; Lv, J. Association between perceived urban built environment attributes and leisure-time physical activity among adults in Hangzhou, China. Prev. Med. 2014, 66, 60-64. [CrossRef] [PubMed]

35. Wells, N.M.; Yang, Y. Neighborhood design and walking: A quasi-experimental longitudinal study. Am. J. Prev. Med. 2008, 34, 313-319. [CrossRef] [PubMed]

36. Montgomery, J. Making a city: Urbanity, vitality and urban design. J. Urban Des. 1998, 3, 93-116. [CrossRef]

37. Cuthbert, A.R. Designing Cities: Critical Readings in Urban Design; Blackwell Publishing: Malden, MA, USA, 2003.

38. Widiastuti, R.; Harsritanto, B.I. Implementing mixed land use rooting jane jacobs'concept of diversity in urban sustainability. Modul 2017, 17, 27-35.

39. Greenwald, M.J.; Boarnet, M.G. Built environment as determinant of walking behavior: Analyzing nonwork pedestrian travel in Portland, Oregon. Transp. Res. Rec. 2001, 1780, 33-41. [CrossRef]

40. Boarnet, M.G.; Greenwald, M.; McMillan, T.E. Walking, urban design, and health: Toward a cost-benefit analysis framework. J. Plan. Educ. Res. 2008, 27, 341-358. [CrossRef]

41. Coogan, P.F.; White, L.F.; Adler, T.J.; Hathaway, K.M.; Palmer, J.R.; Rosenberg, L. Prospective study of urban form and physical activity in the Black Women's Health Study. Am. J. Epidemiol. 2009, 170, 1105-1117. [CrossRef] [PubMed]

42. Boone-Heinonen, J.; Guilkey, D.K.; Evenson, K.R.; Gordon-Larsen, P. Residential self-selection bias in the estimation of built environment effects on physical activity between adolescence and young adulthood. Int. J. Behav. Nutr. Phys. Act. 2010, 7, 70. [CrossRef] [PubMed]

43. Handy, S.; Cao, X.; Mokhtarian, P.L. Self-selection in the relationship between the built environment and walking: Empirical evidence from Northern California. J. Am. Plan. Assoc. 2006, 72, 55-74. [CrossRef]

44. Handy, S.L.; Cao, X.; Mokhtarian, P.L. The causal influence of neighborhood design on physical activity within the neighborhood: Evidence from Northern California. Am. J. Health Promot. 2008, 22, 350-358. [CrossRef]

45. Cao, X.J.; Mokhtarian, P.L.; Handy, S.L. The relationship between the built environment and nonwork travel: A case study of Northern California. Transp. Res. Part A Policy Pract. 2009, 43, 548-559. [CrossRef]

46. Gao, Y.; Liu, K. Planning for diverse slow activities of Shenzhen Greenway. Planners 2019, 35, $39-45$.

47. Meurs, H.; Haaijer, R. Spatial structure and mobility. Transp. Res. Part D Transp. Environ. 2001, 6, 429-446. [CrossRef]

48. Hou, N.; Popkin, B.M.; Jacobs, D.R., Jr.; Song, Y.; Guilkey, D.; Lewis, C.E.; Gordon-Larsen, P. Longitudinal associations between neighborhood-level street network with walking, bicycling, and jogging: The CARDIA study. Health Place 2010, 16, 1206-1215. [CrossRef] [PubMed]

49. Chengdu Codoon Technology Co., Ltd., Chengdu, China. Analysis of the Development of China's Sports Social Platform "Codoon" in 2017. 2017. Available online: https:/ / www.chyxx.com/industry/201709/560616.html (accessed on 8 September 2017). 
50. Shenzhen Bureau of Statistics, Shenzhen, China. Shenzhen Social Gender Statistics Report. 2017. Available online: http: //www.sz.gov.cn/attachment/0/62/62974/1333646.pdf (accessed on 28 April 2017).

51. Liu, K.; Siu, K.W.M.; Gong, X.Y.; Gao, Y.; Lu, D. Where do networks really work? The effects of the Shenzhen greenway network on supporting physical activities. Landsc. Urban Plan. 2016, 152, 49-58. [CrossRef]

52. Langford, M. The areal interpolation problem: Estimating population using remote sensing in a GIS framework. In Handling Geographical Information: Methodology and Potential Applications; Longman Pub Group: London, UK, 1991; pp. 55-77.

53. Mennis, J. Generating surface models of population using dasymetric mapping. Prof. Geogr. 2003, 55, 31-42.

54. Josey, M.J.; Moore, S. The influence of social networks and the built environment on physical inactivity: A longitudinal study of urban-dwelling adults. Health Place 2018, 54, 62-68. [CrossRef] [PubMed]

55. Puhakka, S.; Pyky, R.; Lankila, T.; Kangas, M.; Rusanen, J.; Ikäheimo, T.M.; Koivumaa-Honkanen, H.; Korpelainen, R. Physical activity, residential environment, and nature relatedness in young men-A population-based MOPO study. Int. J. Environ. Res. Public Health 2018, 15, 2322. [CrossRef] [PubMed]

56. Breda, J. Transforming public spaces to promote physical activity-A key contributor to achieving the Sustainable Development Goals in Europe. Eur. J. Public Health 2018, 28 (Suppl. 4), cky213-cky599. [CrossRef]

57. Yue, T.X.; Wang, Y.A.; Liu, J.Y.; Chen, S.P.; Qiu, D.S.; Deng, X.Z.; Liu, M.L.; Tian, Y.Z.; Su, B.P. Surface modelling of human population distribution in China. Ecol. Model. 2005, 181, 461-478. [CrossRef]

58. Steinnocher, K.; Köstl, M.; Weichselbaum, J. Grid-based population and land take trend indicators-new approaches introduced by the geoland 2 core Information Service for Spatial Planning. In NTTS Conference, Brussels; NTTS Conference: Brussels, Belgium, 2011.

59. Zhang, C.; Wan, Q.; Zhang, J.; Okada, N.; Li, H. The method of flood disaster risk evaluation based upon data of grid square. Geo-Inf. Sci. 2003, 4, 69-73.

60. Ellis, G.; Hunter, R.; Tully, M.A.; Donnelly, M.; Kelleher, L.; Kee, F. Connectivity and physical activity: Using footpath networks to measure the walkability of built environments. Environ. Plan. B Plan. Des. 2016, 43, 130-151. [CrossRef]

61. Song, Y.; Rodríguez, D.A. The Measurement of the Level of Mixed Land Uses: A Synthetic Approach; Carolina Transportation Program White Paper Series; University of North Carolina: Chapel Hill, NC, USA, 2005.

62. Saelens, B.E.; Handy, S.L. Built environment correlates of walking: A review. Med. Sci. Sports Exerc. 2008, 40 (Suppl. 7), S550. [CrossRef]

63. Li, P.; Zhang, Y. The size of the Chinese middle class, identity and social attitudes. Society 2008, 28, 1-19.

64. Shanghai Federation of social Science Associations, Shanghai, China. Ranking List of Housing Price to Income Ratio in 35 Large and Medium Cities in China. Available online: http:// finance.sina.com.cn/china/gncj/2016-04-14/doc-ifxriqqv5658227.shtml (accessed on 14 April 2017).

65. Shenzhen Housing and Construction Bureau, Shenzhen, China. Waiting for Application Conditions for Public Rental Housing. Available online: http://zjj.sz.gov.cn/hdjl/ywzs/content/post_3683244.html (accessed on 8 December 2016).

66. Hao, P.; Sliuzas, R.; Geertman, S. The development and redevelopment of urban villages in Shenzhen. Habitat Int. 2011, 35, 214-224. [CrossRef]

67. Gang, W. Research on Housing Affordability: 2000-2008 Evidence from 10 Chinese Cities. Urban Stud. 2009, 9, $20-25$.

68. National Bureau of Statistics, Shenzhen Bureau of Investigation, Shenzhen, China. Shenzhen 2016 National Economic and Social Development Statistical Bulletin. Available online: http://www.sz.gov.cn/cn/xxgk/zfxxgj/tjsj/tjgb/content/post_1333706.html (accessed on 28 April 2017).

69. Wu, Z.-J.; Song, Y.; Wang, H.-L.; Zhang, F.; Li, F.-H.; Wang, Z.-Y. Influence of the built environment of Nanjing's Urban Community on the leisure physical activity of the elderly: An empirical study. BMC Public Health 2019, 19, 1459. [CrossRef] [PubMed]

70. Hanibuchi, T.; Kawachi, I.; Nakaya, T.; Hirai, H.; Kondo, K. Neighborhood built environment and physical activity of Japanese older adults: Results from the Aichi Gerontological Evaluation Study (AGES). BMC Public Health 2011, 11, 657. [CrossRef] [PubMed]

71. Yang, M.; Rosenberg, M.W.; Li, J. Spatial variability of health inequalities of older people in China and related health factors. Int. J. Environ. Res. Public Health 2020, 17, 1739. [CrossRef] [PubMed]

72. Ying, L.; Yin, Z. Quantitative evaluation on street vibrancy and its impact factors: A case study of Chengdu. New Archit. 2016, 1, $52-57$.

73. Feng, J.; Yang, Z. Factors influencing travel behavior of urban elderly people in Nanjing. Prog. Geogr. 2015, 34, 1598-1608.

74. Feidong, L.; Shaohua, T. Built environment's influence on physical activity: Review and thought. Urban Plan. Int. 2015, 30, 62-70.

75. Meteorological Bureau of Shenzhen Municipality, Shenzhen, China. 2015 Shenzhen Climate Bulletin. Available online: http: //weather.sz.gov.cn/qixiangfuwu/qihoufuwu/qihouguanceyupinggu/nianduqihougongbao/content/post_3578341.html. (accessed on 28 February 2016). 